\title{
CONSIDERAÇÕES SOBRE A HISTÓRIA DAS ÁFRICAS NO ESTÁGIO SUPERVISIONADO DE HISTÓRIA (2000-2006, UDESC) ${ }^{1}$
}

\section{CONSIDERATIONS ON THE HISTORY OF AFRICANS IN THE SUPERVISED STAGE OF HISTORY (2000-2006, UDESC)}

Maíra Pires Andrade²

\begin{abstract}
RESUMO: Este artigo investiga as representações sobre a História das Áfricas, expressas pelos estudantes de Graduação em História da UDESC, na condição de estagiários na Educação Básica, nos Relatórios Finais da disciplina de Estágio Supervisionado dos anos 2000 a 2006. Dessa maneira, buscarei entender quais os sentidos e significados do ensino desta temática para os estagiários. Como aporte teórico usarei, principalmente, autores como Fanon, Quijano e Mbembe, para pensar a colonialidade e o racismo na atualidade, e Hall, para mobilizar o conceito de representação. Este artigo é um recorte de uma dissertação em desenvolvimento na UDESC, que perceberá as rupturas, nestes relatórios, antes e depois da aprovação da Lei 10.639/03, estabelecendo relações entre as apropriações dos estagiários, e o que é compreendido pelos estudantes das escolas que são campo de estágio.
\end{abstract}

Palavras-chave: História Africana e Afro Brasileira. Representação. Racismo. Lei 10.639/03.

ABSTRACT: This article investigates the representations on the History of Africa that are expressed by the UDESC undergraduate students in History as trainees in Basic Education that will appear in the Final Reports of the discipline of Supervised Internship from the year 2000 to 2006. In this way, I will try to understand which are the meanings and meanings of the teaching of this subject for trainees. As a theoretical contribution I will mainly use authors such as Fanon, Quijano and Mbembe to think about coloniality and racism in the present and Hall to mobilize the concept of representation. This article is a cut of a dissertation under development at the UDESC that will perceive the ruptures in these reports before and after the approval of Law 10.639/03, establishing relations between the appropriations of the trainees and what is understood by the students of the schools that are field of internship.

Keywords: African and Afro-Brazilian History. Representation. Racism. Law 10.639 / 03.

1 Este artigo é um recorte da dissertação de mestrado "Qual África? A história das Áfricas e as práticas de ensino na UDESC (2000-2015) ".

2 Pesquisadora associada ao Núcleo de Estudos Afro-Brasileiros da Universidade do Estado de Santa Catarina (UDESC). Mestre em História pela Universidade do Estado de Santa Catarina (UDESC). 


\section{Considerações iniciais}

Este artigo investiga as representações sobre a história das Áfricas ${ }^{3}$, expressas pelos estudantes de Graduação em História da UDESC, na condição de estagiários na Educação Básica. Utilizo como documentos históricos os Relatórios Finais de 2000 a 2006, contabilizando um total de 10 relatórios da disciplina de Estágio Supervisionado, do curso de graduação em História da UDESC ${ }^{4}$.

Segue, abaixo, um quadro em que se descreve, respectivamente, o nome dos relatórios analisados neste artigo, os autores, a escola campo de estágio, o bairro em que está localizada, a turma em que as aulas foram aplicadas e o ano de publicação do relatório.

\section{Quadro 1 - Relação de Relatórios de Estágio Analisados de 2000 a 2006}

\begin{tabular}{|c|c|c|c|c|}
\hline Título & Autores & Escola/ Bairro & Ano/Nível & $\begin{array}{l}\text { Ano de } \\
\text { apresentação } \\
\text { do Relatório }\end{array}$ \\
\hline $\begin{array}{l}\text { A música: } \\
\text { cantigas e } \\
\text { histórias da ilha }\end{array}$ & $\begin{array}{l}\text { Alexandre } \\
\text { Martins } \\
\text { Haroldo Silis } \\
\text { Mender da } \\
\text { Silva }\end{array}$ & $\begin{array}{lr}\text { Centro } \quad \text { Cultural } \\
\text { Escrava Anástacia/ } \\
\text { Mont Serra }\end{array}$ & $\begin{array}{c}\text { Não } \\
\text { especificado }\end{array}$ & 2000 \\
\hline $\begin{array}{l}\text { Imigração } \\
\text { Colonização }\end{array}$ & $\begin{array}{l}\text { Cesar } \\
\text { Cancian } \\
\text { Dalla Rosa } \\
\text { Mário } \\
\text { Ernesto } \\
\text { Kuhne } \\
\text { Leda Maria } \\
\text { Fernandes }\end{array}$ & $\begin{array}{ll}\text { Colégio } & \text { de } \\
\text { Aplicação/ Trindade }\end{array}$ & $\begin{array}{l}10 \quad \text { ano } \\
\text { Ensino } \\
\text { Médio }\end{array}$ & 2001 \\
\hline $\begin{array}{l}\text { Relatório } \quad \mathrm{de} \\
\text { Estágio }\end{array}$ & $\begin{array}{l}\text { Evilasia } \\
\text { Poluceno }\end{array}$ & $\begin{array}{l}\text { Colégio } \\
\text { Aplicação/ }\end{array}$ & $\begin{array}{ll}10 & \text { ano } \\
\text { Ensino } & \end{array}$ & 2001 \\
\hline
\end{tabular}

3 Substituo o emprego da expressão História e cultura africana e afro-brasileira pelo termo história das Áfricas na escrita dessa dissertação. Esse termo é utilizado por especialistas a fim de expressar a existência da multiplicidade e heterogeneidade dos sujeitos e das suas histórias, compreendendo as múltiplas histórias africanas que irradiam a partir de uma história multicêntrica e de sujeitos construídos historicamente a partir dos "eus" culturais cruzados. Dessa forma, contribuo para o afastamento da noção preconceituosa de que à África restaria apenas o aspecto cultural, evidenciando as suas multiplicidades (AZEVEDO, 2016).

4 Este trabalho é resultado de um recorte de uma pesquisa de mestrado, que tem como eixo temporal 2000 até 2015, contudo neste recorte utilizarei como documento somente os Relatórios Finais de 2000 à 2006, contabilizando um total de 10 relatórios. 


\begin{tabular}{|c|c|c|c|c|}
\hline & $\begin{array}{ll}\text { Marlen } & \\
\text { Batista De } \\
\text { Martino } \\
\text { Milana } \\
\text { Cristina } \\
\text { Lazzaris } \\
\end{array}$ & Trindade & Médio & \\
\hline \begin{tabular}{l}
\multicolumn{2}{c}{ Violência } \\
hoje e suas \\
raízes sociais no \\
período colonial
\end{tabular} & $\begin{array}{l}\text { Marcia } \\
\text { Claudio } \\
\text { Cardoso da } \\
\text { Silva } \\
\text { Marcos } \\
\text { Anderson } \\
\text { Tedesco } \\
\text { Thiago } \\
\text { Juliano } \\
\text { Sayao }\end{array}$ & \begin{tabular}{lr}
\multicolumn{1}{c}{ Escola } & de \\
Educação & Básica \\
Simão & \\
Hess/Trindade
\end{tabular} & $\begin{array}{l}\quad 2^{\circ} \text { ano } \\
\text { Ensino } \\
\text { Médio }\end{array}$ & 2001 \\
\hline $\begin{array}{l}\text { Á } \\
\text { ditadura, aquele } \\
\text { abraço }\end{array}$ & $\begin{array}{l}\text { Ana } \\
\text { Carolina } \\
\text { Wessler } \\
\text { Prudêncio } \\
\text { da Silva } \\
\text { Ana Laura } \\
\text { Tridapalli } \\
\text { Roberto } \\
\text { Oliveira do } \\
\text { Prado }\end{array}$ & $\begin{array}{l}\text { Escola Anisio } \\
\text { Teixeira/ Costeira }\end{array}$ & $\begin{array}{l}\quad 3^{\circ} \text { ano } \\
\text { Ensino } \\
\text { Médio }\end{array}$ & 2005 \\
\hline \begin{tabular}{lll} 
& \multicolumn{1}{c}{ A } & \\
revolução & & \\
industrial e & a \\
inserção & de \\
Florianópolis na & nodernidade \\
mode
\end{tabular} & $\begin{array}{l}\text { Elisângela } \\
\text { da Silva } \\
\text { Landra } \\
\text { Joel Spcart } \\
\text { José Rada } \\
\text { Neto }\end{array}$ & $\begin{array}{l}\text { Escola Anisio } \\
\text { Teixeira/Costeira }\end{array}$ & $\begin{array}{l}\quad 2^{\circ} \text { ano } \\
\text { Ensino } \\
\text { Médio }\end{array}$ & 2005 \\
\hline $\begin{array}{l}\quad \text { As } \\
\text { experiências da } \\
\text { docência: novas } \\
\text { perspectivas } \\
\text { sobre o ensino } \\
\text { de história }\end{array}$ & $\begin{array}{l}\text { Israel da } \\
\text { Silveira } \\
\text { Kelwyn } \\
\text { Pfleger } \\
\text { Sávio Lopes } \\
\text { Pavanello }\end{array}$ & IEE / Centro & $\begin{array}{l}2^{\circ} \text { ano } \\
\text { Ensino } \\
\text { Médio }\end{array}$ & 2006 \\
\hline 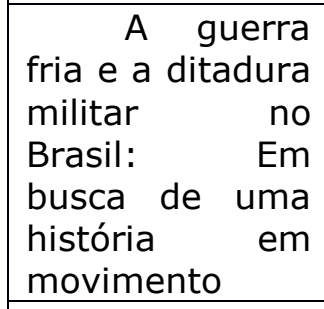 & $\begin{array}{l}\text { Mateus Perez } \\
\text { Jorge } \\
\text { Maro } \\
\text { Schweder } \\
\text { Fábio } \\
\text { Macedo }\end{array}$ & IEE/Centro & $\begin{array}{l}\quad 2^{\circ} \text { ano } \\
\text { Ensino } \\
\text { Médio }\end{array}$ & 2006 \\
\hline \begin{tabular}{l}
\multicolumn{2}{c}{ Escravos, } \\
alemães, \\
subversivos na \\
Ditadura e \\
moradores de \\
favela durante \\
os séculos XIX \\
e XX da história \\
do Brasil e de
\end{tabular} & $\begin{array}{l}\text { Ademir } \\
\text { Soares } \\
\text { Luciano } \\
\text { Junior } \\
\text { Cíntia Ertel } \\
\text { Silva }\end{array}$ & IEE/ Centro & $\begin{array}{l}\quad 1^{\circ} \text { ano } \\
\text { Ensino } \\
\text { Médio }\end{array}$ & 2006 \\
\hline
\end{tabular}




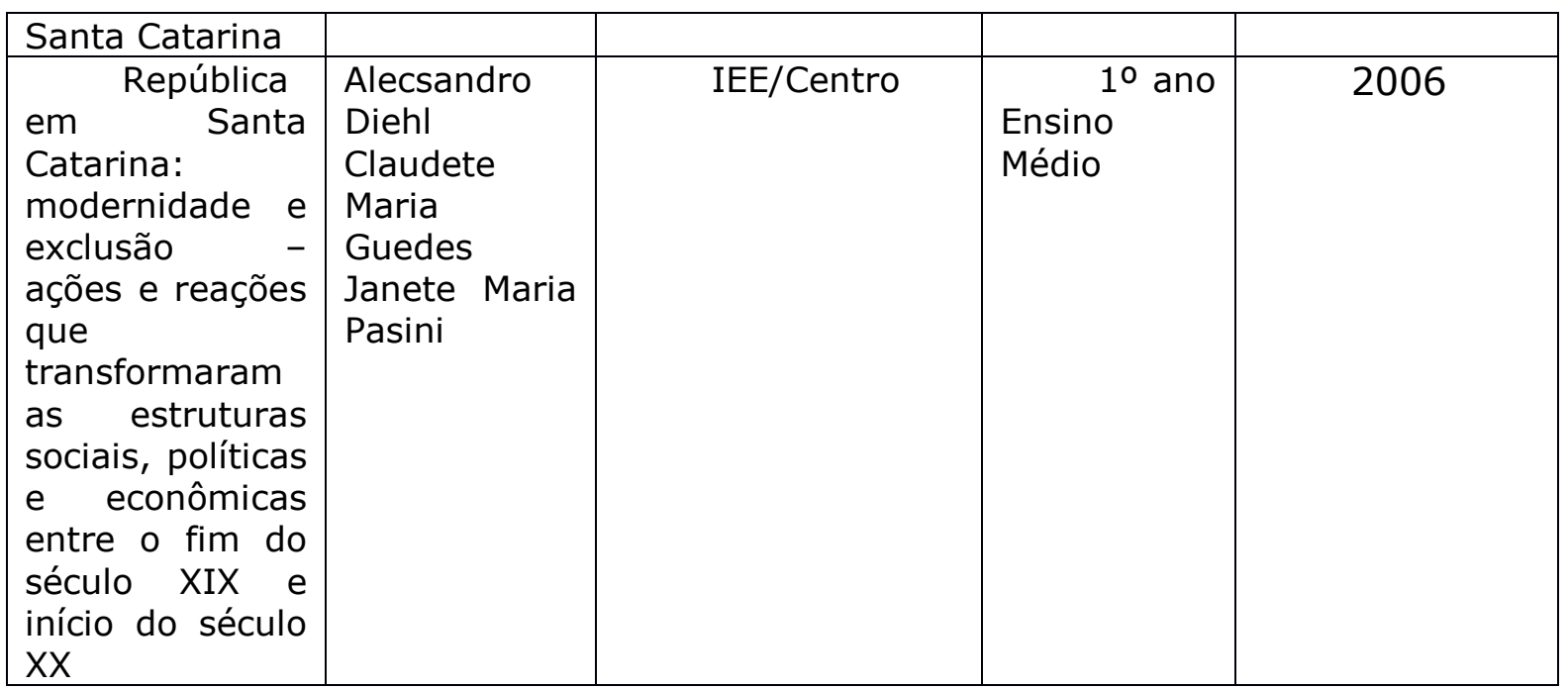

Fonte: Elaborado pela autora, 2016.

\section{Qual África é ensinada no estágio?}

Torna-se imprescindível, antes de iniciar as análises, o entendimento da instituição escolar e da própria disciplina de História ${ }^{5}$, como um elemento da modernidade, com todos os seus mecanismos disciplinadores que corroboram, também, para o controle das subjetividades e do conhecimento, sendo partícipe do projeto colonizador e da modernidade, o qual tem como pilar a matriz eurocêntrica. Esta herança persiste nos dias atuais, seja no currículo escolar como um todo, ou no ensino de História em particular, mesmo que, em menor grau, mas ainda rege, implicitamente, a separação dos conteúdos a serem ensinados, por exemplo, na divisão quadripartite da História (antiga, medieval, moderna e contemporânea), na forma como são ensinados os conteúdos, e os olhares e categorias lançadas a determinadas populações que, desde o passado colonial, são subalternizadas.

O relatório intitulado "A música: cantigas e histórias da ilha", publicado em 2000, foi produzido pelo grupo de estagiários que atuou no Centro Cultural Escrava Anastácia, na Comunidade do Mont Serrat, conhecido como Morro do

5 A disciplina de História, seguindo esta mesma lógica, surgiu como narrativa necessária à constituição das nações europeias, os chamados Estados Nacionais, conformando roteiro que condiciona corpos, saberes, valores e conteúdos indispensáveis para a nação nos moldes civilizatórios desejados (CERRI, 2001). 
Caixa. As aulas pautaram a história de Florianópolis, por meio das músicas e cantigas de roda, apresentando o que seria a cultura local da cidade, procurando desvencilhar-se dos modelos tradicionais que colocam a tradição açoriana como único símbolo cultural da capital. No entendimento desses estagiários, a cultura local compõe-se de elementos próprios e influências múltiplas, mas ainda, assim, colocam que a população açoriana foi o principal elemento formador, adaptado à geografia e aos elementos específicos da cidade, inclusive assimilando outras culturas. Nessa lógica, o relatório de estágio em questão, não é uma expressão da cultura açoriana, mas da cultura local constituída por diversas culturas, principalmente indígena e africana, estas, porém, consideradas assimiladas.

É verdade que os colonizadores açorianos foram o principal elemento de formação do povo que habita a zona litorânea de Santa Catarina, mas também é verdade que este contingente foi obrigado a submeter-se a um árduo processo de adaptação a uma geografia muito diversa da de origem, e só o fez com a assimilação de complexos inteiros de outras culturas. Portanto, nosso trabalho não se trata de nenhuma "manifestação típica açoriana", mas, sim, da cultura local que absorveu elementos de outras culturas, sobretudo das populações indígenas e de origem africana (MARTINS; SILVA, 2000, p. 12, grifo meu). ${ }^{6}$

Mesmo contemplando a parcela da contribuição africana e indígena na constituição da cultura local de Florianópolis, estas ainda aparecem como elementos de união, aglutinação e incorporação à cultura açoriana. A política de assimilação, termo utilizado pelos estagiários, segundo Mbembe (2014), nada mais é do que de-substancializar e estetizar a diferença, sendo os "nativos" incorporados no âmbito da modernidade, "convertidos" e "cultivados", "capazes" de se encaixar num ideal de cidadania. Amílcar Cabral, intelectual e ativista do Pan-africanismo, natural de Guiné-Bissau, evidencia que a política de assimilação é mais uma forma de expressão do racismo:

[...] a dominação colonial tem procurado criar teorias, as quais, de fato, são apenas grosseiras formulações de racismo. [...] Este, por exemplo, é o caso da chamada teoria da assimilação progressiva das populações nativas, o que acaba sendo unicamente uma mais

\footnotetext{
6 Nos trechos retirados dos relatórios optei por manter a grafia original, conforme a escrita de estagiários e estudantes.
} 
ou menos violenta tentativa de negar a cultura dos povos em questão (CABRAL, 1973, p. 40).

Os estagiários se apropriaram do entendimento de que diferentes culturas entrecruzadas formulam a cultura local da cidade, uma compreensão positiva, e alternativa criativa, à imposição da colonialidade e do racismo, mas que resulta na desconsideração das culturas não europeias. Mantém, em seus usos, a cultura açoriana como elemento hegemônico, enquanto as populações indígenas e africanas surgem como secundárias, assimiladas e cooptadas. De acordo com Fanon (2008), o racismo pode ser compreendido como elemento de vasta opressão sistematizada em diversas escalas e dimensões, inclusive, selecionando o que pode visto como elemento cultural preponderante, como é o caso do elemento açoriano, elevado na narrativa dos estagiários.

Portanto, mesmo com as apropriações e "maneiras de fazer", os estagiários, no presente, ainda reproduzem a lógica colonialista do passado, constituído por teorias e práticas coloniais e imperialistas, baseadas em estruturas racistas, sexistas, classistas e hierárquicas.

O desafio do ensino de história das Áfricas envolve a construção de um conhecimento que reafirme a atuação destas populações para a formação do país, assim como os não africanos e não indígenas. De igual forma, a utilização de alguns conceitos, quando não aprofundados e problematizados, podem ser apropriados de maneira errônea pelos estudantes. Ou, apropriados de modo a esquecer o real sentido do conceito, como o caso do termo assimilação. Por isso, se torna fundamental o apontamento do significado desta palavra, a fim de evidenciar aos estudantes todo o processo de colonização, inclusive a sua face violenta.

O relatório de título "A revolução industrial e a inserção de Florianópolis na modernidade" trata da experiência de estágio no Colégio Estadual Anísio Teixeira, no $2^{\circ}$ ano do Ensino Médio, publicado em 2005. O objetivo das aulas era compreender o processo da Revolução Industrial no século XVIII, atrelado aos ideais de modernidade e ciência, e a percepção das modificações nas 
relações sociais, comerciais e culturais em Florianópolis, assim como no próprio espaço urbano (LANDRA; SPCART; RADA NETO, 20057).

Este projeto não propôs abordar nenhum elemento específico vinculado à história das Áfricas ou das populações de origem africana ${ }^{8}$. No entanto, é meu papel como historiadora perceber as ausências e, também, as entrelinhas do documento. Nessa lógica, observei que a partir do objetivo principal das aulas, os estagiários abordaram os antagonismos presentes nos conceitos de modernidade, moderno e atrasado, no âmbito das inovações trazidas com a Revolução Industrial.

Pensar o nosso tema implica trabalhar conceitos como Modernidade e Revolução, bem como moderno e atrasado, a partir da própria realidade dos alunos, trazendo como exemplos práticos situações corriqueiras da vida como um aparelho de toca-discos, de toca-fitas, de $C D$, etc. A problematização não deve ser utilizada apenas para introduzir o assunto, mas deve ser utilizado como prática (LANDRA; SPCART; RADA NETO, 2005, p. 60).

As representações e a produção de significados estão sempre envoltas numa relação de poder e, por meio da linguagem e de nossos próprios sistemas de significação, criamos o sentido e o signo das coisas. Deste modo, diversos significados são constituídos a partir de relações opostas e, assim, inscritos em conceitos binários, deslocando corpos, sentimentos, medos ou repulsas, dependendo do modo como o significado é lido e interpretado, nos diferentes contextos como, por exemplo, o conceito de atrasado, citado no excerto anterior.

Ao tratar do conceito de representação, afirmando ser uma prática que produz efeitos sobre os sujeitos, Hall destaca que a cultura se formula como processo de disputas de significados, concretizada por meio da linguagem. Com

7 A escolha da temática do estágio não sofreu intervenção do professor regente da turma (LANDRA; SPCART; RADA NETO, 2005).

8 No intuito de buscar uma alternativa aos termos racializados, optei por utilizar os termos afrodescendentes ou populações de origem africana em substituição do termo negro. O termo populações de origem africana ou afrodescendentes remete, segundo Paulino Cardoso (2008), a experiências amplas de diferentes povos e vivências, incluindo a própria experiência da diáspora africana. Desse modo, ampliarei as experiências destes para além da escravidão, devolvendo a estes atores históricos, do passado e do presente a humanidade que muitas vezes a eles foi negada. No entanto, tomando cuidado com a historicidade do termo negro, irei, em determinados momentos, quando me referir às questões levantadas ou citadas pelo movimento negro, utilizar este termo, contribuindo politicamente para a luta antirracista (SANTOS, 2016). 
isso, exponho o caráter político das representações em diferentes âmbitos da sociedade, como os conceitos de moderno e atrasado, oriundos de um período em que se desejava construir uma determinada imagem da Europa, o "modelo de civilização" (HALL, 2003).

Trouxe à tona esta reflexão no sentido de pensar como podemos olhar a história das Áfricas com base em conceitos alicerçados na noção de progresso. A partir disso, quais as representações formadas na mente dos alunos, referentes à história das Áfricas, a partir das explicações de que o moderno é bom e o atrasado é obsoleto/ruim? Destaco que a representação está na base da construção das identidades, então como estes alunos mobilizaram estes conceitos ao pensar as populações africanas e afrodescendentes, sendo que estas possuem outros modos de ser e de estar no mundo? Será mesmo possível enquadrar estes conceitos para estas populações? Quais identidades formuladas a partir destas representações? Cada conceito possui uma história e um contexto de criação, assim como uma intenção, necessitando de abordagem complexa para serem tratados em sala de aula.

Outra questão, "esquecida" quando pensamos em modernidade, é sua face colonial e violenta, o que é pertinente ser esquecido e excluído quando se constitui a modernidade.

A Modernidade é um projeto muito rico, capaz, inclusive, de movimentos contraditórios e complexos. A Modernidade é, portanto, a afirmação total e irrestrita da técnica e da ciência transformando a vida e as relações da humanidade. Mostremos imagens de esculturas, quadros... a Modernidade mudou toda a concepção e o jeito de pensar e agir humano [...]. A exclusão social no Brasil, e, especialmente, em Florianópolis, será discutida por meio da divisão da cidade, sobretudo, após a construção da Avenida do Saneamento em 1940 (Herćlio Luz), e a nova a configuração da cidade. Vamos falar dos antigos bairros, sua localização e as populações que foram "empurradas" para os morros. Teremos imagens e fotos para mostrar. Acentuaremos as manifestações do transporte coletivo na cidade, traremos fotos de revistas e artigos de jornais para problematizar e contextualizar como se construiu a exclusão e a desigualdade social, desencadeando estas formas de contestação (LANDRA; SPCART; RADA NETO, 2005, p. 68). 
Nessa perspectiva, o relatório em questão atenta para a ciência constituída na inserção da modernidade, e suas consequências, no que diz respeito à exclusão social. Os estagiários explicitaram a existência dessa exclusão, mas não evidenciaram os grupos ou as pessoas excluídas. Torna-se urgente apresentar as faces que acompanham o ideal de progresso, modernidade, $e$ as ideias inovadoras do século XIX, caso contrário, continuaremos escrevendo uma história eurocêntrica. A representação da modernidade, pelo viés do desenvolvimento, é uma construção política e intencional, expressando o poder simbólico e cultural da representação, na medida em que aloca a Europa como detentora do moderno, e classifica e categoriza todo o mundo como atrasado (HALL, 2003).

A partir dessas questões, é preciso pensar qual a memória constituída e reforçada a partir dos escritos desses estagiários, e de suas práticas em sala de aula. As discussões teóricas sobre memória, de modo geral, partem de bases epistemológicas europeias que, como afirma Karla Andrezza Vieira Vargas (2016), impõem uma concepção de conhecimento e, também, de valorização de determinada concepção de memória, embasada nos ideais modernos, europeus, brancos, ocidentais e cristãos. Spivak (2010), sobre este argumento, aborda a existência de um "sujeito teórico" para o entendimento dos elementos constituintes da memória. Neste sentido, trata-se de tarefa difícil pensar as relações da memória a partir de autores de outros locais de enunciação.

Hampaté-Bâ (2010) traz o papel fundamental da memória na tradição africana pertencente aos povos de cultura oral, mas este é elemento importante para toda a humanidade, estabelecendo uma relação complexa entre esquecimento, lembrança e imaginação. Ampliando o debate sobre a memória, Antonacci (2013) expande o leque de possibilidades de enunciação. Compreendendo o corpo, enquanto memória, a autora apresenta como as populações de origem africana ancoram, e expressam, suas memórias para além de um documento escrito, na corporeidade, oralidade, comunicação, ritmo, música, voz, recursos linguísticos e artísticos, elementos que nos obrigam a pluralizar acervos históricos, monumentos e patrimônios. Nesse aspecto, pontuo que a memória constituída a partir do saber histórico, dos conteúdos históricos e 
da prática docente configurada nestes relatórios, incide, também, nas diversas ancoragens destas memórias.

Para Paul Ricouer (2007), a memória possibilita aos indivíduos o entendimento da sua história, da sua temporalidade e do seu passado, entretanto, ao estabelecer a rememoração de alguns fatos, também, permite o esquecimento. Nesse sentido, há um desafio, pois, a mesma memória que lembra, também causa o esquecimento e, ao reconstituir algo do passado, alguns elementos, pessoas, fatos ou eventos são apagados ou reconfigurados. $O$ lembrar e o esquecer também estão no campo das disputas de poder, e de memória, construindo o que deve ser lembrado, quais tipos de memória necessitam ser rememorados e qual a concepção de memória contada. Como exemplo, ao longo da construção da história brasileira, o privilégio de uma memória dita "oficial", constantemente descartou a memória transmitida por outros suportes de enunciação, como a oralidade.

Lembrar do passado das populações imigrantes europeias que adentraram no Brasil e, em detrimento, esquecer ou minimizar a grande parcela de africanos e afrodescendentes que também deixaram a sua marca, a sua memória e a sua corporeidade $^{9}$ na história brasileira, constituiu prática intencional em diversos momentos da história do Brasil. Quando se propunha o embranquecimento da população brasileira, por exemplo, havia embates e conflitos em direção à constituição de uma dada memória hegemônica. Nos excertos trazidos anteriormente, de modo intencional ou não, o esquecimento ou a perpetuação de uma dada memória, de tanto ser reproduzida no âmbito coletivo, tornou-se projeção real no cotidiano das pessoas. Amparar-se nessa memória da colonização de Florianópolis, e da região de Santa Catarina, entendida como plenamente açoriana, alemã ou italiana, constrói, também, um equívoco sobre a presença de descendentes de africanos.

Nessa perspectiva, a opção da descolonização do pensamento fornece indícios fundamentais para questionamento destas narrativas hegemônicas no ensino de História. A descolonização, nas palavras de Mignolo (2003), não produz uma versão "mais verdadeira" da história em oposição a uma "suposta

\footnotetext{
9 A concepção da memória ancorada nos corpos, constitui discussão aprofundada na obra de Antonacci (2013).
} 
mentira", mas caminha na construção de uma narrativa que atente para a percepção de uma outra lógica, com a mudança de termos, conceitos, questionamentos e paradigmas, inclusive repensando o que se compreende como memória.

Este esquecimento não ocorre apenas quando surge a temática da imigração, mas também quando saímos da ótica do conteúdo e ampliamos as lentes para analisar os programas elaborados pelos estagiários. Aparecem algumas indagações: por que às escolas são oferecidos determinados conteúdos específicos? Como os currículos de História operam no sentido de selecionar para que, o que e como ensinar História? Quais os temas, os objetos e as metodologias que os professores escolhem para fazer as mediações entre o passado e o presente vivido por nós?

Tais questões permitem perceber como a História ensinada é resultado de um recorte, temporal, histórico ou cultural, fruto de seleções, a partir de sujeitos históricos inseridos num espaço social (FONSECA, 2007). Nessa acepção, o conteúdo escolar, assim como a História, não é neutro, e o currículo "é sempre parte de uma tradição seletiva, um perfeito exemplo de invenção da tradição". (GOODSON, 1995, p. 27). O ensino tendencioso, motivado pela circulação de saberes, normas e valores da sociedade e, por consequência, do espaço escolar, incide na prática do professor, do aluno e nas representações formuladas a partir disto. Nesta conjuntura, pergunto o que está sendo ensinado no espaço escolar, e por que comumente "esquecemos" de falar sobre a África?

No relatório embasado no projeto chamado "À ditadura, aquele abraço", realizado no 30 ano do Colégio Estadual Anísio Teixeira, e publicado no ano de 2005, o objetivo das aulas era abordar o período da Guerra Fria, destacando transformações, para além da questão política e, especificamente, a Ditadura Militar no Brasil. Nesta linha, os objetivos específicos do projeto direcionaram-se à contextualização dos movimentos contestatórios do período, relacionando-os, principalmente, às lutas feministas e pela liberdade sexual (SILVA; TRIDAPALLI; PRADO, 2005) ${ }^{10}$.

\footnotetext{
10 A temática orientada pela escola para o período de estágio foi a Guerra Fria (SILVA; TRIDA PALLI; PRADO, 2005).
} 
Para chegar a estes objetivos, os estagiários aplicaram um questionário, em que indagavam os temas, dentro do período da guerra fria, que mais despertavam o interesse dos alunos. Dentre esses temas estavam listados: Chegada do Homem à Lua, Queda do Muro de Berlim, Corrida Armamentista, Movimento Hippie, Golpe de 64, Construção de Brasília, Repressão na Ditadura no Brasil, Guerra do Vietnã, Cuba Socialista e A descolonização da África. Na análise descrita pelos estagiários, os temas de maior interesse pelos alunos, com $21 \%$ do total de 17 alunos, foram: Chegada do Homem à Lua, Queda do Muro de Berlim, Corrida Armamentista e Movimento Hippie.

Em segundo plano constavam os temas: Golpe de 64, Construção de Brasília e Repressão na Ditadura no Brasil. (SILVA; TRIDA PALLI; PRADO, 2005). Os estagiários colocaram, em anexo, somente dois destes questionários. Em relação a estes, especificamente, a preferência dos temas aparece como descrita pelos estagiários, sendo o tema descolonização da África indicado como de menor interesse. Na própria análise dos estagiários, da lista de preferências dos alunos, a descolonização de África não foi sequer citada, nem para reafirmar a falta de interesse dos alunos por esta temática.

Diante disso, fica a questão: qual motivo deste desinteresse e esquecimento notado nos relatórios acima? Seria o racismo constantemente reproduzido, por meio do silenciamento e desconhecimento em relação às Áfricas? Conforme Mignolo (2003) e, também, as contribuições de Fanon (2005), aqui citadas, o colonialismo e o eurocentrismo andam juntos, sendo este último a raiz reprodutiva da colonialidade do saber, que controla o conhecimento e a subjetividade, por consequência, as histórias e saberes locais oriundos da Europa são concebidos como projetos globais, colocando o continente como ponto de referência. Fanon (2005) nos alerta que é o colono ou o europeu que escreve a história, esta história não é a história do local que foi saqueado pela ação europeia, mas é a história da sua nação neste território, ou seja, é o prolongamento da história da sua metrópole, no caso a Europa. Nesse aspecto, a experiência de outros continentes, como a África, é negada, esquecida e até mesmo vista como "não sendo tão importante", repercutindo num desconhecimento, e, também, falta de interesse, que não deixa de ser resultado 
da permanência do racismo epistemológico ou, de modo mais amplo, da colonialidade do saber na atualidade.

No relatório de autoria de Dihel, Guedes e Pasini (2006), também é notável este fenômeno. Num questionário aplicado com os alunos no início do estágio, uma das questões indagava sobre o período da história que os alunos mais gostavam de estudar ou gostariam de estudar. Entre as respostas, dentre os 15 alunos, apenas um fazia alusão a um elemento das Áfricas, com a presença do Egito na resposta: "Sim. O Egito. Sempre me interessei por mistérios e artefatos antigos" (DIHEL; GUEDES; PASINI, 2006, p. 66). As outras respostas giravam em torno de História Moderna, descobrimento do Brasil e História Contemporânea.

O Egito que desperta o interesse no estudante, é antigo, com faraós e pirâmides, imagem de uma representação pautada no passado e no imobilismo, conectada às dimensões do significado, da linguagem e da cultura. Nesse sentido, é preciso perceber significados produzidos a partir destas representações, não como mera imaginação da nossa mente, mas produtores de efeitos reais em práticas e condutas, sendo necessário questionar estes signos (HALL, 2003).

A partir das concepções de Antonacci (2013), a ideia do Egito imóvel embasa-se em classificações excludentes, feitas na obra de Filosofia da História de Hegel, em 1831, separando o histórico do pré-histórico, atribuindo à África a porção sem história do mundo. Para Hegel, o continente africano não possui história, nem movimentos ou progressos, conformando espaço congelado no tempo. Logo, para Antonacci (2013), a África na atualidade é a mesma do passado, uma África presa ao imobilismo histórico.

A colonialidade incide, também, na inserção da Europa como centro até mesmo nos processos em que os africanos foram os principais agentes. No relatório intitulado "A Guerra Fria e a Ditadura Militar no Brasil: em busca de uma história em movimento", publicado em 2006, e executado no $2^{\circ}$ ano do ensino médio no IEE $^{11}$, o plano de aula sobre a descolonização afro-asiática tinha como objetivo mostrar que a conjuntura europeia não conseguia mais ter

11 O professor regente da turma não interferiu na escolha da temática selecionada pelos estagiários (JORGE; SCHWEDER; MACEDO, 2006). 
recursos para manter as colônias, ocorrendo, assim, a descolonização. Em suma, toda a ação dos africanos que lutaram e constituíram movimentos de descolonização, como o movimento Pan-africanista, foi omitido.

Nesse contexto, observo como os estagiários se apropriaram dessa racionalidade ocidental e, ao fabricar suas ideias, formularam outras "maneiras de fazer" dessa racionalidade, construindo e disseminando "outros modos" de usar o saber eurocêntrico. Desse modo, concordamos com as contribuições de Quijano (2009), para quem o eurocentrismo não é uma perspectiva presente apenas nos europeus, mas também em quem foi educado por eles. Nas narrativas apreendidas na escola, como apresentado no excerto do relatório a seguir, esta lógica também se manifesta.

Quanto ao tema de descolonização Afro-Asiatica, será levado em conta a mudança de conjuntura pós 1945, onde a Europa, destruída e preocupada com seu processo de reconstrução, não teve mais como manter as suas possessões, tanto no continente africano como asiático (JORGE; SCHWEDER; MACEDO, 2006, p. 89).

A conjuntura explicitada assemelha-se, sobremaneira, à questão da Abolição da escravidão no Brasil, mencionada pela historiografia como resultado da ação de uma heroína branca, a princesa Isabel, apagando movimentos de resistência e ação, executados por africanos e afrodescendentes escravizados que, também, pressionaram as elites para a Abolição. A atuação histórica e social destes atores é desfigurada e moldada à representação de que eram passivos. Mbembe (2014) pontua que o hemisfério ocidental, sobretudo a Europa, ao ambicionar tornar-se potência hegemônica, construiu um mito de superioridade para fundamentar seu poder, colocando-se, enquanto detentora e berço da razão, da vida universal, da real humanidade.

Em oposição a isso, o resto, como denominado por este mesmo autor, era a diferença pura, o poder negativo, a África símbolo da vida vegetal, do vazio, ou como afirmava Hegel, os africanos eram estátuas sem consciência de si, completamente a-históricos. Tal imaginário, repetido e reproduzido ao longo do tempo, contribuiu para uma historiografia que atribui aos africanos escravizados a passividade e a coisificação, desconsiderando toda a ação destes personagens no decorrer da história. 
A representação do trecho acima expressa a junção da colonialidade do saber e do ser, sendo o conhecimento europeu a referência e o espaço de ação deste também, ao passo que dos africanos retira-se a participação na história da descolonização do seu próprio continente. Atentar aos significados produzidos com esta representação, implica repensar práticas, condutas, normas e a própria construção das identidades (HALL, 2003). Nesse âmbito, é importante compreender práticas moduladas quando africanos são encaixados como inativos ou passivos.

Considero indispensável uma reflexão sobre as divisões de conteúdo na disciplina de História, pois o que compreendemos como História Moderna ou Medieval, na Europa, não é equivalente ao o que ocorreu nas Áfricas no período respectivo. Hountondji (2009), traz contribuições fundamentais, ao indagar, se estamos estudando discursos históricos sobre a África, ou um discurso histórico proveniente de África e produzido por africanos. Concordando com o filósofo anglo-ganes Kwame Anthony Apiahh (1997) e com o Martinicano Fanon (2008), o questionamento do eurocentrismo não significa sua substituição pelo modelo afrocêntrico, pois o ponto chave não é substituir o olhar europeu por um olhar puramente africano da história.

Este movimento pretende evidenciar, numa perspectiva que pense além da raça e da cor, as interpretações das experiências de diferentes indivíduos e lócus de enunciação. Deste modo, uma das estratégias constitui vislumbrar um ensino de história das Áfricas que não seja isolado, estático e repleto de referências negativas, possibilitando problematizar a necessidade de apresentarmos novos modos de aprender a história, caso contrário, não faz sentido ensinar a história da África a partir de um olhar puramente europeu, até porque esta tem sido a lógica presente há séculos.

Pensando na importância de nos interrogarmos sobre a percepção das populações africanas acerca das narrativas históricas, considero substancial o exemplo trazido pelos estagiários elencados a seguir. Uma das atividades desenvolvidas no relatório de autoria de Poluceno, Martino e Lazzaris (2000), realizado no $1^{0}$ ano do Ensino Médio, no Colégio de Aplicação, publicado em 
$2000^{12}$, é a análise de um poema de autoria de Mario Prata, chamado "Pequena História". O documento traz uma perspectiva notável de crítica à visão de uma Europa e dos brancos como centro do mundo, demonstrando uma apropriação, por parte dos estagiários, em relação as estas temáticas e abordagens.

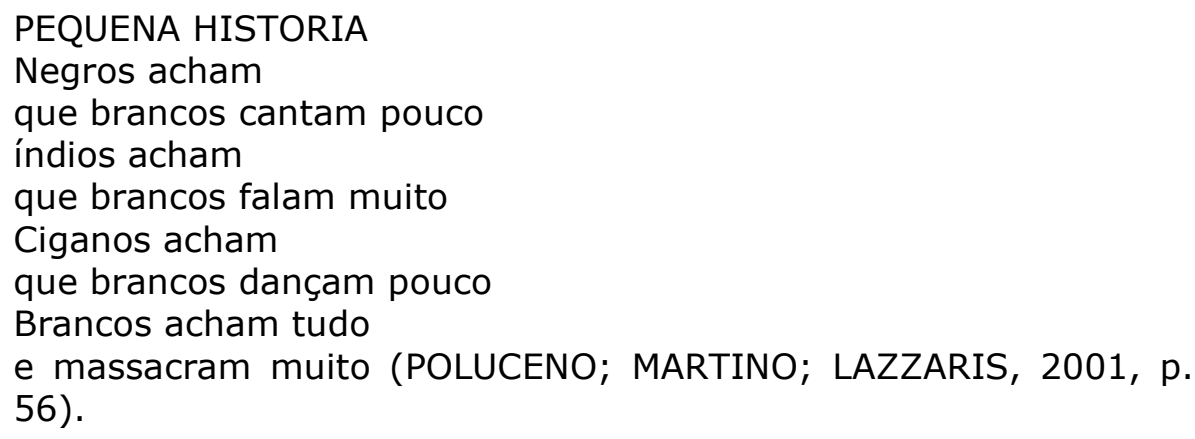

O poema traz à tona o olhar de populações oprimidas e subalternizadas pelos brancos, permitindo aos estudantes a reflexão sobre a existência dessas perspectivas antagônicas e, de como a história escrita ampara-se numa visão branca e europeia. Em outras palavras, os estagiários, ao buscar a criação de estratégias para desviar do fator dominante, produzem, inventam ou fabricam diferentes modos de fazer emergir este espaço de reflexão.

A perspectiva eurocêntrica de ver o mundo e, por consequência, o racismo epistemológico, enraíza-se em diversos níveis de interpretação da realidade, principalmente, no que concebemos como ciência e conhecimento, deste modo, selecionando, o que de acordo com esta visão, é conhecimento, arte, civilização, cultura, e o que não é. Tal processo desumaniza as populações de origem africana, enquadrando-as sempre ao lado negativo e bárbaro do binarismo e, assim, construindo a superioridade e a civilidade da Europa (ANTONACCI, 2013). É necessário problematizar estas distinções e desconstruí-las ao se tratar de história das Áfricas, caso contrário, não encontraremos história no continente africano, mas apenas "cultura" e "folclore".

Neste artigo, elucidei os "lados" da história propositalmente "esquecidos", silenciados ou colocados em segundo plano, "lado" a que pertence o continente

12 O conteúdo orientado pelo professor regente, para o trabalho e abordagem dos estagiários, enquadrava-se no século XIX, no Brasil, a partir do qual o recorte do conteúdo foi a escravidão (POLUCENO; MARTINO; LAZZARIS, 2001). 
africano. Nesse aspecto, enfatizo o risco de ensinar uma história das Áfricas desvinculada de questões que permeiam esta história, como, por exemplo, se o professor não discutir, no âmbito da Guerra Fria, a descolonização da África, ou no período da colonização, a participação africana na constituição do país, o que ele referencia quando indagado sobre a história das Áfricas? Fica a questão. Na mesma linha da invisibilização das experiências africanas, é substancial apontar o quanto estas são contadas a partir de um olhar exterior, dos europeus, ainda uma expressão do silenciamento dirigido a estas populações.

Neste artigo, foi possível verificar os diversos modos, como que a história das Áfricas são esquecidas, silenciadas ou diminuídas no contexto escolar. É percebido, num primeiro momento, a representação da ausência desta imagem da África, quando não é nomeada, citada ou referenciada nos diferentes conteúdos de História, ou ainda aparece em menor exposição, quando comparada com outros conteúdos. Num segundo momento, aparece nas aulas dos estagiários a referência a populações afrodescendentes na história, mas, ainda assim, aparecem em segundo plano ou após uma longa explanação sobre colonização europeia, sendo expressa por apenas uma palavra ou citação, ou seja, permanece a representação deste como uma menor relevância na história.

Num terceiro momento, é notável a representação dos africanos como indivíduos sem ação, desumanizados e sem a agência histórica, delegando ao europeu a capacidade de contar sua história. Isto pode ser observado no trecho em que a descolonização da África se torna resultado apenas da ação dos europeus, apagando toda a ação dos africanos.

Em suma, foi evidenciado neste artigo que a história das Áfricas e a história da população afrodescendente quando não está ausente, seja pelo desinteresse dos estudantes em estudos sobre a temática, ou pela falta de preparo dos estagiários, surge a partir do seu significado para a escravidão, isto é, os estagiários a compreendem a partir da sua vinculação com o regime escravista no Brasil.

No que diz respeito a valorização dos afrodescendentes e do seu papel como agentes históricos na construção do Brasil, demanda reivindicada ao longo do tempo pelos movimentos sociais e que, também, emerge na LDB, os relatórios analisados exprimem a branquitude presente em nossas relações ao 
colocarem a atuação destes em menor escala em relação aos brancos. Do mesmo modo, foi observado na abordagem direcionada a disciplina de História, o uso de categorias sustentadas pela epistemologia eurocêntrica, sem devida reflexão, o que corrobora com o olhar opressor à história dos afrodescendentes, preponderante na atualidade. Na dissertação completa, tenho como objetivo verificar os Relatórios de 2000 até 2015 e, dessa forma, averiguar se o impacto da Lei incidiu, de alguma maneira, nas aulas dos estagiários e nas representações dos estudantes.

\section{Referências}

ANTONACCI, Maria Antonieta. Memórias ancoradas em corpos negros. São Paulo: EDUC, 2013.

APPIAH, Kwame Anthony. Na casa de meu pai. Rio de Janeiro: Contraponto, 1997.

AZEVEDO, Amailton Magno. Imagens da África: entre a violência discursiva e a produção da memória. Boletim do Tempo Presente, nº 06, p.1-10, set., 2013.

AZEVEDO, Amailton Magno. Qual África ensinar no Brasil? Tendências e perspectivas. Projeto História, São Paulo, n. 56, p. 233-255, maio-ago., 2016.

CABRAL, Amilcar. Return to the Source. New York: Edited by Africa Information Service, Monthly Review Press, 1973.

CARDOSO, Paulino de Jesus Francisco. Negros em Desterro: experiências de populações de origem africana em Florianópolis, 1860-1888. Tese (Doutorado em História) - Pontifícia Universidade Católica, São Paulo, 2008.

CERRI, Luis Fernando. Os conceitos de consciência histórica e os desafios da didática da história. Revista de História Regional, Ponta Grossa, v. 6, n. 2, p. 93$112,2001$.

DIEHL, Alecsandro; GUEDES, Claudete Maria; PASINI, Janete Maria. República em Santa Catarina: modernidade e exclusão - ações e reações que transformaram as estruturas sociais, políticas e econômicas entre o fim do século XIX e início do século XX. Relatório de Estágio Supervisionado. Florianópolis: UDESC, 2006.

FANON, Frantz. Pele negra máscaras brancas. Tradução de Renato da Silveira. Salvador: Editora da UFBA. 2008.

FANON, Frantz. Sobre a violência. In: . Os Condenados da Terra. Juiz de Fora: Ed. UFJF, 2005. 
FONSECA, Selva G. Didática e prática de ensino em História. São Paulo: Papirus, 2007.

GOODSON. Ivor F. Currículo - teoria e história. Petrópolis: Vozes, 1995.

HALL, Stuart. Da diáspora - identidades e mediações. Belo Horizonte: Editora UFMG, 2003.

HAMPATÉ-BÂ, Amadou. A tradição viva. In: KI-ZERBO, J. (Coord.). História Geral da África I. Metodologia e Pré-História da África. 2. ed. Brasília: UNESCO, 2010. p. 181-212.

HOUNTONDJU, Paulin J. Conhecimento de Africa, conhecimentos de africanos. In: SANTOS, Boaventura de Sousa; MENESES, Maria Paula (Org.). Epistemologias do Sul. Coimbra: Edições Almedina S.A., 2009. p. 119-132.

JORGE, Mateus Perez; SCHWEDER, Maro; MACEDO, Fábio. A guerra fria e a ditadura militar no Brasil: Em busca de uma história em movimento. Relatório de Estágio Supervisionado. Florianópolis: UDESC, 2006.

LANDRA, Elisangela da Silva; SPCART, Joel; RADA NETO, José. A revolução industrial e a inserção de Florianópolis na modernidade. Relatório de Estágio Supervisionado. Florianópolis: UDESC, 2005.

LUCIANO JUNIOR, Ademir Soares; SILVA, Cintia Ertel. Escravos, alemães, subversivos na Ditadura e moradores de favela durante os séculos XIX e XX da história do Brasil e de Santa Catarina. Relatório de Estágio Supervisionado. Florianópolis: UDESC, 2006

MARTINS, Alexandre; SILVA, Haroldo Silis Mender. A música: cantigas e histórias da ilha. Relatório de Estágio Supervisionado. Florianópolis: UDESC, 2000.

MBEMBE, Achille. Crítica a razão negra. Lisboa: Editora Antígona, 2014.

MIGNOLO, Walter D. Histórias locais/Projetos globais: colonialidade, saberes subalternos e pensamento liminar. Belo Horizonte: UFMG, 2003.

POLUCENO, Evilasia; MARTINO, Marlen Batista de; LAZZARIS, Milana Cristina. Relatório de Estágio. Relatório de Estágio Supervisionado. Florianópolis: UDESC, 2001.

QUIJANO, Anibal. Colonialidade do poder e classificação social. In: SANTOS, Boaventura de Sousa; MENESES, Maria Paula (Org.). Epistemologias do Sul. Coimbra: Edições Almedina, 2009. p. 73-118.

RICOUER, Paul. A memória, a história, o esquecimento. Tradução Alain François. Campinas: Editora da UNICAMP, 2007.

ROSA, Cesar Cancian Dalla; KUHNE, Mário Ernesto; FERNANDES, Leda Maria. Imigração e colonização. Relatório de Estágio Supervisionado. Florianópolis: UDESC, 2001. 
SANTOS, Carina Santiago dos. A Educação das Relações Étnico-Raciais e o ensino de História na Educação de Jovens e Adultos da Rede Municipal de Florianópolis (2010-2015). 2016. 131f. Dissertação (Mestrado em Ensino de História) - Universidade do Estado de Santa Catarina. Florianópolis, 2016.

SILVA, Ana Carolina Wessler Prudencio; TRIDAPALLI, Ana Laura; PRADO, Roberto Oliveira do. Á ditadura, aquele abraço. Relatório de Estágio Supervisionado. Florianópolis: UDESC, 2005.

SILVA, Marcia Claudio Cardoso; TEDESCO, Marcos Anderson; SAYAO, Thiago Juliano. Violência hoje e suas raízes sociais no período colonial. Relatório de Estágio Supervisionado. Florianópolis: UDESC, 2001.

SILVEIRA, Israel da; PLEGER, Kelwyn; PAVANELLO, Sávio Lopes. As experiências da docência: novas perspectivas sobre o ensino de história. Relatório de Estágio Supervisionado. Florianópolis: UDESC, 2006.

SPIVAK, Gayatri. Pode um subalterno falar? Belo Horizonte: UFMG, 2010.

VARGAS, Karla Andrezza Vieira. Vozes, Corpos e Saberes do Maciço: Memórias e Histórias de vida das populações de origem africana em territórios do Maciço do Morro da Cruz/Florianópolis. 2016. 121f. Dissertação (Mestrado em Ensino de História) - Universidade do Estado de Santa Catarina. Florianópolis, 2016. 